\title{
Research on the Evaluation and Development Strategy of Environmental Logistics in Hebei Province
}

\author{
ZiYu LIU ${ }^{1}$, JianYue XUE ${ }^{2}$ \\ ${ }^{1}$ Hebei University of Science and Technology School of Economics and Management Shijiazhuang China \\ ${ }^{1}$ Hebei University of Science and Technology School of Economics and Management Logistics Engineering Langfang China
}

\begin{abstract}
Environmental logistics has become the irreversible trend of logistics development in the future, and it is also an inevitable choice to promote the transformation of China's modern logistics industry. Regions that want to develop environmental logistics must scientifically evaluate the current status of environmental logistics development. This paper builds a regional environmental logistics evaluation system, horizontally compares the data of Hebei Province and 13 other provinces in 2017, and longitudinal evaluation of data from 2013 to 2017 in Hebei Province, and obtains the ranking of the development status of environmental logistics in Hebei Province and its development trend in the past five years. Based on the evaluation results, countermeasures and suggestions are proposed for improving the level of environmental logistics in Hebei Province, including increasing the comprehensive utilization rate of waste; reinforcing the investment in related fixed assets; reducing the energy consumption of the logistics industry; improving the operating mileage of public railways, and increasing the freight volume.
\end{abstract}

\section{Introduction}

With the vigorous development of China's logistics industry, the pollution problem of logistics industry cannot be ignored. The good development of environmental logistics will promote the development of environment and economy. Evaluating the development status of regional environmental logistics can make the region realize scientific management. On the other hand, the evaluation results can clarify its own advantages, learn about the deficiencies of the region in the process of developing environmental logistics, find the focus of future work, and help to improve and develop environmental logistics in the region. Therefore, this paper analyzes and evaluates the development status of environmental logistics in Hebei Province, clarify its advantages and disadvantages, put forward countermeasures and suggestions based on the evaluation results, and promote its development.

\section{Research status of Environmental Logistics Evaluation}

\subsection{Status of Research}

At present, the research on environmental logistics evaluation has made some achievements. Some scholars study from a management perspective. Scholars pointed out that companies are interested in sustainable development activities. They established a quantitative evaluation model to measure the uncertainty of environmental supply chain management activities, and proposed indicators of environmental design, production, procurement, recycling, transportation and warehousing [1]. Scholars studied the vehicle routing problem, and the proposed indicators include vehicle type, delivery time, transportation cost, and fuel type [2]. Scholars proposed that enterprises should eliminate waste in the production process. The indicators they proposed include electricity consumption, water consumption, carbon dioxide emissions, and the proportion of waste [3]. Some scholars studied from the perspective of reverse logistics. Scholars studied the main factors affecting the evaluation of environmental protection degree, and designed a reasonable evaluation index system for green degree. They used Fuzzy Analytical Hierarchy Process (FAHP) and Fuzzy Comprehensive Evaluation Method (FCEM), and selected indicators including environmental, resource, economic, technical and social perspectives [4]. Some scholars studied from the perspective of regional environmental logistics evaluation. Scholars conducted a performance evaluation of environmental logistics in six provinces and one city in East China. The indicators proposed include the mileage of railway operations, water consumption, and exhaust emissions of the logistics industry [5]. The indicators proposed include the number of education, scientific research and consulting institutions, the quantity of transportation tools, and the recycling rate of raw materials [6]. Some scholars have studied from the perspective of supply chain. Scholars established indicators from the four aspects of enterprise cooperation ability, logistics service quality, resource 
utilization ability and enterprise environmental protection ability, considering indicators include enterprise information level, warehouse space utilization rate, waste recovery utilization rate, etc [7]. Scholar considered the four aspects of packaging, warehousing, transportation, and recycling. The indicators proposed include energy saving rate, average storage cost, and velocity of goods circulation [8].

\subsection{Literature Review}

At present, many scholars put forward different evaluation indexes of environmental logistics. The literature on evaluating regional environmental logistics from the macro level lacks unified standards, and some indicator data is difficult to find, so it is difficult to scientifically and objectively evaluate the development of regional environmental logistics. This paper constructs regional environmental logistics evaluation indicators that are easy to find and generally applicable.

\section{Index system evaluating environmental logistics development}

On the basis of referring to relevant literature and combining with practice, the evaluation index system of regional environmental logistics is established according to the principle of evaluation index construction. The establishment of index system evaluating environmental logistics development should not only consider economic factors, but also consider all aspects of logistics. Which should include the selection of indicators from the four aspects of the logistics industry, respectively are economic, facility, environmental and operational factors.

In terms of economic factors, the logistics industry, as a sunrise one, has made important contributions to the operation of the national economy. The amount of fixed asset investment in the logistics industry and fixed asset investment in environmental protection will affect the regional development of the logistics industry. Therefore, the indicators selected in this paper in terms of economic factors are logistics GDP, logistics fixed asset investment, ecological protection and environmental governance fixed asset investment.

In terms of facilities, the current status of infrastructure reflects environmental logistics capabilities. Infrastructure plays an an indispensable role in regional development of environmental logistics, which generally includes packaging, transportation, storage and other links. The mileage of highway operation and railway operation and per capita rate of civil vehicles can reflect the environmental logistics capacity, so the indicators selected in terms of facilities include the operating mileage of public railways and per capita ownership rate of civil vehicles.

In terms of environmental factors, the comprehensive utilization rate of waste affects the development of regional environmental logistics. Similarly, the energy consumption of logistics industry can also reflect the development of regional environmental logistics to a certain extent. Therefore, the indicators selected in terms of environmental factors are the comprehensive utilization rate of waste and the energy consumption of the logistics industry.

In terms of operational factors, operational capabilities affect the development of regional environmental logistics. The number of employees in the logistics industry is an indicator considered from the internal operating factors of the logistics industry, and the freight volume and freight turnover are the indicators considered from the operating factors of the logistics industry. Therefore, the indicators selected in terms of operational factors include the number of employees in the logistics industry, freight volume, and freight turnover.

In summary, ten indicators were selected to construct index system evaluating environmental logistics development. The details are shown in Table 1.

Table1. Index system evaluating environmental logistics development

\begin{tabular}{|c|c|}
\hline $\begin{array}{c}\text { Primary } \\
\text { indicators }\end{array}$ & Secondary indicators \\
\hline \multirow{3}{*}{$\begin{array}{l}\text { Economic } \\
\text { factors }\end{array}$} & GDP of logistics industry $C_{1}$ \\
\hline & Fixed assets investment in logistics industry $\mathrm{C}_{2}$ \\
\hline & $\begin{array}{c}\text { Investment in fixed assets for ecological protection and } \\
\text { environmental governance } \mathrm{C}_{3}\end{array}$ \\
\hline \multirow{2}{*}{$\begin{array}{l}\text { Facility } \\
\text { factors }\end{array}$} & Operating mileage of highway and railway $\mathrm{C}_{4}$ \\
\hline & Per capita ownership rate of civil vehicles $\mathrm{C}_{5}$ \\
\hline \multirow{2}{*}{$\begin{array}{l}\text { Environme } \\
\text { ntal factors }\end{array}$} & Comprehensive utilization rate of waste $\mathrm{C}_{6}$ \\
\hline & Energy consumption of the logistics industry $\mathrm{C}_{7}$ \\
\hline \multirow{3}{*}{$\begin{array}{l}\text { Operationa } \\
1 \text { factors }\end{array}$} & Number of employees in logistics industry $\mathrm{C}_{8}$ \\
\hline & Freight volume $\mathrm{C}_{9}$ \\
\hline & Freight turnover $C_{10}$ \\
\hline
\end{tabular}

\section{Fuzzy Analysis of Environmental Logistics in Hebei Province Based on Gray Correlation Degree}

Gray fuzzy comprehensive evaluation is a method to judge things or phenomena with uncertain factors without fully understanding its information. The specific steps are as follows.

Firstly, the weight $\mathrm{P}$ is determined, and the $\mathrm{k}$-th element in the index system $\mathrm{C}$ is compared with other elements, its importance is scaled from 1-9, and scale value for the ratio of the elements in line $\mathrm{k}, \mathrm{U}_{\mathrm{k} 1}, \mathrm{U}_{\mathrm{k} 2}, \ldots$, $\mathrm{U}_{\mathrm{km}}$ can be obtained to judge the scale values. That is (1), then (2), and $\mathrm{P}$ will be obtained. Secondly, the optimal index set $C^{*}$ is determined, and the optimal value of each index are being dimensionless (normalization). According to the (3) correlation coefficient are calculated to get $\mathrm{R}$, generally $\rho=0.5$ in formula. Finally, $B=P \times R=\left(b_{1}, b_{2}, \cdots\right.$, $b_{n}$ ), then evaluate the development of environmental logistics based on the size of $b_{i}$.

$$
\begin{aligned}
& P_{j}=\frac{P_{k}}{U_{k j}},(\mathrm{j}=1,2, \ldots, \mathrm{m})(1) \\
& P_{k}=\left(\sum_{j=1}^{m} U_{k j}\right)^{-1}
\end{aligned}
$$




$$
\eta_{j(i)}=\frac{\Delta(\min )+\rho \Delta(\max )}{\left|C_{i}^{*}-C_{j i}\right|+\rho \Delta(\max )}
$$

This study selects 14 regions' (Hebei, Hubei, Hunan, Fujian, Anhui, Henan, Sichuan, Jiangxi, Hainan, Shanxi, Xinjiang, Guangdong, Jiangsu, Shandong Province) data in 2017 and the data of Hebei Province from 2013 to 2017 for environmental logistics evaluation (The data of 2017 comes from the Statistical Yearbook 2018 of each province, and the data of Hebei Province in the period from 2013 to 2017 comes from the Hebei Economic Statistical Yearbook.) According to the 2017 regional GDP ranking of China, the regions which its GDP above 3 trillion yuan and its per capita GDP is subject to Hebei Province and fluctuate within 5000 US dollars, are selected to research for their comparability.

In the evaluation of environmental logistics, the element index set is $\mathrm{C}=\left\{\mathrm{C}_{1}, \mathrm{C}_{2}, \cdots, \mathrm{C}_{10}\right\}$, and $\mathrm{C}_{\mathrm{i}}(\mathrm{i}=1,2, \cdots$, $10)$ is the indicator of the $\mathrm{i}$-th factor.

$$
R_{1}=\left[\begin{array}{ccccccc}
0.606 & 0.435 & 0.444 & 0.496 & 0.381 & 0.540 & 0.4 \\
0.464 & 0.564 & 0.463 & 0.551 & 0.421 & 0.507 \\
0.428 & 0.799 & 1 & 0.451 & 0.386 & 0.954 & 0.1 \\
0.518 & 0.713 & 0.626 & 0.404 & 0.544 & 0.711 \\
0.795 & 0.373 & 0.333 & 0.465 & 0.367 & 0.433 & 0.37 \\
0.445 & 0.615 & 0.707 & 0.480 & 0.901 & 0.581 & 0.3 \\
0.645 & 0.498 & 0.536 & 0.648 & 0.662 & 0.512 & 0.5 \\
0.625 & 0.361 & 0.577 & 0.342 & 0.340 & 1 & 0.45 \\
0.523 & 0.470 & 0.518 & 0.413 & 1 & 0.524 & 0.4 \\
0.482 & 0.385 & 0.364 & 0.390 & 0.451 & 0.407 & 0.35
\end{array}\right.
$$

4.2.2 Fuzzy Evaluation: According to $\tilde{\mathrm{P}}, \tilde{\mathrm{R}}$, it can obtained that $\tilde{B}=(0.5138,0.5883,0.6596,0.4757,0.5014$, $0.6931,0.5408,0.4260,0.4177,0.4245,0.4265,0.5790$, $0.5218,0.6929)$. That is $b_{6}>b_{14}>b_{3}>b_{2}>b_{12}>b_{7}>b_{13}>b_{1}>$ $b_{5}>b_{4}>b_{11}>b_{8}>b_{10}>b_{9}$, that is based on the comprehensive evaluation of the above 10 evaluation factors, the ranking order of the development of environmental logistics in 14 provinces and cities is: Henan, Shandong, Hunan, Hubei, Guangdong, Sichuan, Jiangsu, Hebei, Anhui, Fujian, Xinjiang, Jiangxi, Shanxi, Hainan.

Hebei Province ranks seventh in the overall ranking. Among the various indicators, its relative advantages are as follows: number of employees in logistics industry and turnover of freight traffic rank second, per capita ownership rate of civil vehiclesranks third, GDP of logistics industry ranks fourth, and the freight volume ranks fifth. However, the indicators of investment in fixed assets for ecological protection and environmental governance, energy consumption of the logistics industry, operating mileage of highway and railway, fixed assets investment in logistics industry, and comprehensive

\subsection{Determination of weight "P"}

According to the experts' comparison with other factors based on the comprehensive utilization rate of waste $\left(\mathrm{C}_{6}\right)$, the importance scale values among the factors are given. The scale value in column 6 of judgement ratio matrix is $\mathrm{U}_{6}=\left\{\mathrm{U}_{16}, \mathrm{U}_{26}, \mathrm{U}_{36}, \mathrm{U}_{46}, \mathrm{U}_{56}, \mathrm{U}_{76}, \mathrm{U}_{86}, \mathrm{U}_{96}, \mathrm{U}_{106},\right\}$, thus the weight value of factor $\mathrm{C}_{6}$ is $\mathrm{P}_{6}=1 / 25 . \tilde{\mathrm{P}}=(1 / 25,4 / 25,8 / 25$, $1 / 25,1 / 25,1 / 25,3 / 25,2 / 25,2 / 25,2 / 25)$.

\subsection{A Comparative Analysis among Hebe Province and Other Regions}

\subsubsection{Inverse Calculation Based on Correlation} Coefficient: According to the practical significance of each index factor, it is obvious that the value of other factors should be large except $C_{7}$. Thus: $C^{*}=\{2497.88$, 4467, 3046235, 334782, 0.201, 94.13, 3607.82, 268.68, $403426,27920\}$, after dimensionless it can obtained that $\mathrm{R}_{1}$.

$\left.\begin{array}{lccccccc}6 & 0.380 & 0.333 & 0.397 & 0.364 & 1 & 0.775 & 0.842 \\ & 0.352 & 0.338 & 0.333 & 0.450 & 0.742 & 0.564 & 0.799 \\ 6 & 0.368 & 0.333 & 0.380 & 0.375 & 0.366 & 0.447 & 0.839 \\ & 0.474 & 0.333 & 0.448 & 0.514 & 0.577 & 0.466 & 0.719 \\ 1 & 0.336 & 0.393 & 0.552 & 0.498 & 0.620 & 1 & 0.863 \\ 0 & 0.340 & 0.362 & 0.333 & 0.377 & 0.739 & 1 & 0.667 \\ 7 & 0.766 & 1 & 0.656 & 0.668 & 0.333 & 0.452 & 0.439 \\ 3 & 0.436 & 0.334 & 0.435 & 0.333 & 0.375 & 0.380 & 0.363 \\ 3 & 0.434 & 0.333 & 0.472 & 0.375 & 0.945 & 0.511 & 0.714 \\ 9 & 0.363 & 0.333 & 0.363 & 0.344 & 1 & 0.418 & 0.426\end{array}\right]$

utilization rate of waste rank low, which have a lot of room for improvement.

\subsection{A Comparative Analysis of Hebei Province in the Past Five Years}

4.3.1 Inverse Calculation Based on Correlation Coefficient: $C^{*}=\{2497.88,2116,1241629,194043$, $0.188,57.6,1109,202.2,277840,13382\}$, after dimensionless it can obtained that $\mathrm{R}_{2}$.

4.3.2 Fuzzy Evaluation: According to $\mathrm{P} 、 \mathrm{R}$, it can obtained that $\tilde{B}=(0.837,0.588,0.547,0.519,0.523)$. That is $b_{1}>b_{2}>b_{3}>b_{4}>b_{5}$. The development of environmental logistics in Hebei Province has been on the rise in recent five years. 


$$
R_{2}=\left[\begin{array}{ccccc}
1 & 0.333 & 0.781 & 0.892 & 0.348 \\
1 & 0.567 & 0.363 & 0.333 & 0.876 \\
1 & 0.682 & 0.467 & 0.333 & 0.376 \\
1 & 0.669 & 0.478 & 0.436 & 0.333 \\
1 & 0.717 & 0.521 & 0.418 & 0.333 \\
1 & 0.715 & 0.945 & 0.350 & 0.333 \\
0.455 & 0.333 & 0.978 & 1 & 0.626 \\
0.333 & 1 & 0.747 & 0.807 & 0.333 \\
0.447 & 0.370 & 0.333 & 0.501 & 1 \\
1 & 0.398 & 0.337 & 0.625 & 0.333
\end{array}\right]
$$

By comprehensively analyzing the above 10 evaluation factors, it can be seen that the development of environmental logistics in Hebei Province in the past five years has generally been increasing year by year. Among them, the index of fixed assets investment in logistics industry, investment in fixed assets for ecological protection and environmental governance, operating mileage of highway and railway, per capita ownership rate of civil vehicles, comprehensive utilization rate of waste trend to ascent, GDP logistics industry and turnover of freight traffic show a tortuous upward trend; energy consumption of the logistics industry and freight volume have been a downward trend.

\section{Suggestions on the Development of environmental Logistics in Hebei Province}

Based on the above analysis, it can be seen that the factors of comprehensive utilization rate of waste, fixed assets investment in logistics industry and investment in fixed assets for ecological protection and environmental governance have restricted the development of environmental logistics. In addition, high energy consumption of the logistics industry, as well as low operating mileage of highway and railway and freight volume, which are the reason why the development of environmental logistics in Hebei Province is hindered. Therefore, on the one hand, comprehensive utilization rate of waste, fixed assets investment in logistics industry and investment in fixed assets for ecological protection and environmental governance, as well as the operating mileage of highway and railway and freight volume need to be improved; on the other, energy consumption of the logistics industry should be reduced vigorously. At the same time, pay attention to railway and highway operation mileage and freight volume.

\subsection{Suggestions on Increasing the Comprehensive Utilization Rate of Waste}

Firstly, the generation of waste in the logistics industry should be reduced to increase the comprehensive utilization of waste. Enterprises and related institutions should strengthen scientific and technological innovation research on the comprehensive utilization of waste and develop comprehensive waste treatment technology. At the same time, the investment and research on new environmentally friendly materials in the logistics industry shall be enhanced, the study of waste recycling, and other technologies to improve the recycling rate of waste in the logistics industry should be researched in depth. As a result, the amount of final waste will be decreased.

The development of environmental logistics needs the strength of the government. Therefore, the government should control the development of environmental logistics from a macro perspective.

Secondly, the government can draw on foreign experience to formulate relevant laws and regulations, which should regulate the disposal of waste and limit the final waste. In addition, the minimum treatment utilization rate should be specified, and the amount of waste generated by the logistics industry should be strictly limited.

Finally, it is possible for government to promote the development of environmental logistics by initiating relevant policies (such as increasing subsidies for comprehensive utilization of waste, tax revenue support, the loan preferential policies), and then promoting the logistics industry to increase comprehensive utilization rate of waste.

\subsection{Suggestions on Reinforcing the Investment in Related Fixed Assets}

The increase in fixed assets provides impetus for economic development, so fixed assets investment in logistics industry and investment in fixed assets for ecological protection and environmental governance need to be strengthened. In order to achieve it, the government can carry out reasonable new construction, expansion, reconstruction, demolition and construction of the logistics industry infrastructures; increase investment in fixed assets such as highway construction, road network reform, rural highway, coastal area construction, and coastal port construction. It should mobilize relevant departments of ecological protection and environmental governance in Hebei Province to actively support and cooperate with the construction of environmental logistics in order to reinforcing the investment in related fixed assets.

\subsection{Suggestions on Reducing Energy Consumption of the Logistics Industry}

The factors that affect the energy consumption of the logistics industry mainly include economic development level, logistics industry development, energy conversion techniques and other factors. The increase of energy consumption and the level of economic development have basically maintained the same growth. Energy consumption has provided protection for economic development. Therefore, the principle of economic construction as the center must be adhered to ensure the safety of energy supply. The fundamental way to reduce 
the energy consumption of logistics industry is to promote the lightweight and energy-saving structure of the logistics industry. Energy consumption of the logistics industry cannot be limited to traditional fossil energy sources. It must transform from relying on a single energy source to multiple energy sources and increase the use of clean energy. Furthermore, enterprises and relevant departments should intensify research and development of new energy sources and improve energy efficiency.

\subsection{Suggestions on Improving the Operating Mileage of Public Railways, and Increasing the Freight Volume.}

The government should improve the technical and economic level of highways and railways in Hebei Province, build a well-managed road and railway network, and improve the transportation capacity and efficiency of it. At the same time, it is also necessary to promote the supply-side structural reform of highways and railways in Hebei Province and inject new vitality into it. The government can increase its research on road and railway technology innovation, accelerate the construction of a strong province on transportation, and lay a solid foundation for improving the level of environmental logistics in Hebei Province. On the other hand, it is necessary to optimize the transportation structure, increase in infrastructure investment, guarantee the transportation capacity, and reduce the empty return load ratio, thereby increasing the freight volume.

\section{Summary}

Nowadays, the environmental logistics of Hebei Province is still facing a series of problems, such as how to reduce pollution. Therefore, when developing environmental logistics, Hebei Province must pay attention to increasing the comprehensive utilization rate of waste, reinforcing the investment in related fixed assets, reducing energy consumption of the logistics industry, improving the operating mileage of public railways, and increasing the freight volume. If Hebei Province can achieve the above points, it will create a broader space for the development of its environmental logistics.

\section{References}

1. Reza Rostamzadeh, Kannan Govindan, Ahmad Esmaeili, Mahdi Sabaghi, "Application of fuzzy VIKOR for evaluation of green supply chain management practices" Malaysia, vol. 2, pp. 188-203, February 2015.

2. S. Ubeda, F.J.Arcelus, J. Faulin, "Green logistics at Eroski:A case study" Spain, vol. 1, pp. 44-51, June 2011.

3. Brunilde Verrier, Bertrand Rose a, Emmanuel Caillaud, Hakim Remita, "Combining organizational performance with sustainable development issues: the Lean and Green project benchmarking repository" France, vol. 1, pp. 83-93, June 2014.
4. Payman Ahi, Cory Searcy,"An analysis of metrics used to measure performance in green and sustainable supply chains" Canada, vol. 1, pp. 360-377, June 2015.

5. Xie A-hong,XUE Qian-yu,ZHOU Ze-tong, "Research on performance evaluation and influencing factors of regional green logistics"China, vol. 2, pp. 44-49, June 2019.

6. DU Dao-hua,ZHENG Guo-hua,ZHANG Limin, "Construction of the environmental logistics evaluation indicator system based onthe dual-oriented society" China, vol. 4, pp. 13-17, April 2011.

7. OUYANG Lu, "Evaluation index research on green logistics service providerbased on logistics service supply chain” China, vol. 5, pp. 12-15, May 2019.

8. XU Qing-qing, "Problems and countermeasures of green logistics development in China" China, vol. 21, pp. 35-38, June 2019. 